\title{
Sunburns among beachgoers in the northern coast of Peru: frequency and factors associated
}

\author{
Eliana L Fernandez-Quiroz ${ }^{1,2}$, Lizeth Gonzales-Chachapoyas ${ }^{1,2}$, Ana L Alcantara-Diaz ${ }^{3}$, Binz Bulnes-Villalta ${ }^{1,2}$, \\ Zulmy Ayala-Porras ${ }^{3}$, Carlos J Toro-Huamanchumo ${ }^{\text {Corresp. } 4,5}$ \\ 1 Universidad Católica Santo Toribio de Mogrovejo, Chiclayo, Peru \\ ${ }^{2}$ Asociación Científica de Estudiantes de Medicina de la Universidad Católica Santo Toribio de Mogrovejo - ASOCIEM USAT, Chiclayo, Peru \\ 3 Sociedad Científica de Estudiantes de Medicina Veritas, Chiclayo, Peru \\ 4 Unidad para la Generación y Síntesis de Evidencias en Salud, Universidad San Ignacio de Loyola, Lima, Peru \\ 5 Unidad de Investigación Multidisciplinaria, Clínica Avendaño, Lima, Peru \\ Corresponding Author: Carlos J Toro-Huamanchumo \\ Email address: ctoro@usil.edu.pe
}

Background: Overexposure to ultraviolet (UV) radiation has increased skin cancer incidence and the risk of sunburns, especially during the summer months.

Objective: Identify the frequency and factors associated with sunburns in a sample of beachgoers in the northern coast of Peru.

Methods: We conducted a secondary data analysis of a previous study that assessed the awareness, behavior and attitudes concerning sun exposure among beachgoers. We included adults between 18 and 59 years who went to a beach in northern Peru during summer (March 2018). Three generalized linear models of the Poisson family were constructed to evaluate the factors associated with having had at least one sunburn last summer. All regression models reported the adjusted prevalence ratio (aPR) with their respective $95 \%$ confidence interval $(95 \% \mathrm{Cl})$.

Results: Of a total of 402 participants, $225(56.0 \%)$ had one to five sunburns and 25 (6.2\%) had six or more. Beachgoers who were 1-15 days (aPR: 1.16, 95\% Cl: 1.05-1.27) or more than 15 days (aPR: 1.22 , $95 \% \mathrm{Cl}: 1.09-1.36$ ) exposed to the sun on the beach had a higher frequency of at least one sunburn. The non-regular wearing of a hat or cap also increased the frequency of sunburns (aPR: $1.06,95 \% \mathrm{Cl}$ :

1.01-1.12). In contrast, those who had Skin Phototype III (aPR: 0.94, Cl 95\%: 0.88-0.99) or IV (aPR: 0.69, $95 \% \mathrm{Cl}: 0.63-0.75)$ had a lower frequency of sunburns.

Conclusion: Three out of five beachgoers had one or more sunburns in the last summer. The factors associated with a higher frequency were the time of sun exposure at the beach and the non-regular use of a hat or cap. Type III-IV skin phototypes were associated with a lower sunburn frequency. 
1 Sunburns among beachgoers in the northern coast of Peru: Frequency and factors

2 associated

3

4 Eliana L. Fernandez-Quiroz ${ }^{1,2}$, Lizeth Gonzales-Chachapoyas ${ }^{1,2}$, Ana L. Alcantara-Diaz ${ }^{3}$, Binz

5 Bulnes-Villalta ${ }^{1,2}$, Zulmy Ayala-Porras ${ }^{3}$, Carlos J. Toro-Huamanchumo ${ }^{4 *}$

6

$7 \quad{ }^{1}$ Universidad Católica Santo Toribio de Mogrovejo, Chiclayo, Peru

$8{ }^{2}$ Asociación Científica de Estudiantes de Medicina de la Universidad Católica Santo Toribio de

9 Mogrovejo - ASOCIEM USAT, Chiclayo, Peru

10 33Sociedad Científica de Estudiantes de Medicina Veritas, Chiclayo, Peru

$11{ }^{4}$ Clínica Avendaño, Unidad de Investigación Multidisciplinaria, Lima, Peru

$12{ }^{5}$ Universidad San Ignacio de Loyola, Unidad para la Generación y Síntesis de Evidencias en

13 Salud, Lima, Peru

16 Short title: Sunburns among beachgoers

18 Corresponding author:

19 Carlos J. Toro-Huamanchumo

20 Clínica Avendaño. Av. Leonidas Avendaño 116, Miraflores 15074, Peru

21 Mobile: +5194494288

22 E-mail: toro2993@hotmail.com 


\section{ABSTRACT}

24 Background: Overexposure to ultraviolet (UV) radiation has increased skin cancer incidence and 25 the risk of sunburns, especially during the summer months.

26 Objective: Identify the frequency and factors associated with sunburns in a sample of beachgoers 27 in the northern coast of Peru.

28 Methods: We conducted a secondary data analysis of a previous study that assessed the awareness, 29 behavior and attitudes concerning sun exposure among beachgoers. We included adults between 3018 and 59 years who went to a beach in northern Peru during summer (March 2018). Three 31 generalized linear models of the Poisson family were constructed to evaluate the factors associated 32 with having had at least one sunburn last summer. All regression models reported the adjusted 33 prevalence ratio (aPR) with their respective 95\% confidence interval (95\% CI).

34 Results: Of a total of 402 participants, $225(56.0 \%)$ had one to five sunburns and $25(6.2 \%)$ had 35 six or more. Beachgoers who were 1-15 days (aPR: 1.16, 95\% CI: 1.05-1.27) or more than 15 days 36 (aPR: 1.22, 95\% CI: 1.09-1.36) exposed to the sun on the beach had a higher frequency of at least 37 one sunburn. The non-regular wearing of a hat or cap also increased the frequency of sunburns 38 (aPR: 1.06, 95\% CI: 1.01-1.12). In contrast, those who had Skin Phototype III (aPR: 0.94, CI 95\%: 39 0.88-0.99) or IV (aPR: 0.69, 95\% CI: 0.63-0.75) had a lower frequency of sunburns.

40 Conclusion: Three out of five beachgoers had one or more sunburns in the last summer. The 41 factors associated with a higher frequency were the time of sun exposure at the beach and the non42 regular use of a hat or cap. Type III-IV skin phototypes were associated with a lower sunburn 43 frequency.

44 Key Words: Sunburn, Ultraviolet Rays, Sunscreen, Skin, Peru.

\section{BACKGROUND}


46 Skin cancer incidence has increased in the last decades (1). In 2018, more than a million new non47 melanoma skin cancer cases were reported worldwide (2), and for melanoma, there is an estimate 48 of 132000 new cases per year (3). Additionally, according to current evidence, the economic 49 burden per patient who receives skin cancer treatment is considerably high, making it a significant 50 public health problem (4-6).

51

52 Peru is one of the countries with the highest ultraviolet (UV) radiation due to its proximity to the 53 equator (7). The National Meteorology and Hydrology Service in Peru (SENAMHI, in Spanish) 54 has confirmed that the UV radiation index has reached levels as high as 19, on a scale of 0-20, 55 mainly in coastal regions (8). In addition, skin cancer has risen from fourth place (period 200656 2011) (9) to third place in the list of the most frequent types of cancer independent of sex (in 2017) 57 (10).

58

59 Current evidence has shown the relationship between overexposure to UV radiation and skin 60 cancer $(11,12)$. This risk factor is usually more frequent in people who go to the beaches during 61 the summer season (13), representing a high-risk population. Previous studies have shown that 62 beachgoers have less adherence to the use of sun protection measures than other populations, 63 additionally to their prolonged exposure to UV radiation in summer months (14-17). These 64 inappropriate attitudes and practices may act as risk factors for sunburns and later development of 65 skin cancer (18-20).

67 Previous studies conducted in adult populations have reported a frequent lifetime history of at least 68 one sunburn $(11,21,22)$, with beachgoers as the highest risk group $(23,24)$. Sun sensitivity, a 69 younger age, having a high perceived vulnerability to skin cancer, and having had a full-body skin 70 examination by a physician have been reported as factors associated with sunburns among US 71 adults (11,21). Similarly, a younger age, male sex, secondary or university education, skin 72 phototypes I-III, midday sun exposure, and lousy sun protection habits have been reported as 73 predictors of sunburns among Spanish beachgoers (24). However, we have not found local studies 74 that assess the association between modifiable and non-modifiable risk factors with sunburns, 75 especially among this population of interest. 
77 This study aimed to determine the frequency and factors associated with sunburns in a sample of 78 beachgoers in the northern coast of Peru.

79

80 METHODS

81 Study design

82 This is a secondary data analysis of a previous study that assessed the awareness, behavior and 83 attitudes concerning sun exposure among beachgoers in the northern coast of Peru (23).

84

85 Study population and procedures

86 We selected from the database the adults surveyed during their visit to Pimentel, which has one of

87 the most crowded beaches in Lambayeque. This region has a semi-warm and tropical-dry climate, 88 with temperatures peaks of $30^{\circ} \mathrm{C}$ since $2014(8,25)$.

89

90 For the primary study, a total of 410 participants $\geq 18$ years old were enrolled using a convenience 91 sampling strategy. The research team applied the "Beach Questionnaire" during the summer 92 season (March 2018), between 08:00 and 16:00 hours. More information about the study 93 population, context and procedures has been previously described in this journal (23). We decided 94 to include only adults between $18-59$ years old $(n=402)$ for the present study. We did not have 95 missing values.

96

\section{Outcome}

98 The outcome variable "sunburn" was defined as an episode of painful reddening of the skin after 99 sun exposure in the last summer (24). 


\section{Independent variables}

102 The following independent variables were included in the analysis: 1) Sociodemographic 103 variables: age (young adult: 18-29 years, and adult: 30-59 years), sex (male and female), 104 nationality, level of education (None/school and higher education), marital status 105 (single/widowed/divorced/separated and married/cohabiting); 2) Skin phototype from the

106 Fitzpatrick model and classified into four categories (I - IV) according to the erythema and tanning 107 response after one hour of sun exposure in the summer $(24,26)$; 3) Sun exposure habits in the last 108 two summers were assessed as: days spent sunbathing on the beach (none, 1-15 days, and >15 109 days), and hours per day exposed to the sun on the beach ( $<30 \mathrm{~min}, 30 \mathrm{~min}$ to 1 hour, and $>1$ hour); 110 4) Sun protection practices in the beach (use of an umbrella, wear a hat or cap, wear long-sleeved 111 clothes, avoid sun exposure in hours between 12:00 and 16:00, and use of sunscreen with a sun 112 protection factor $\geq 15$. These sun protection practices were dichotomized into regular (always or 113 usually) and non-regular (sometimes, rarely, or never). We did not include the variable "use of 114 sunglasses" (as in the primary study) since we consider there is no plausible relationship between 115 this variable and sunburns.

\section{Statistical analysis}

118 According to the history of sunburns in the last summer (none and $\geq 1$ sunburn ). For categorical 119 variables, we used Chi-square and Fisher tests. To assess the factors associated with having had at 120 least one sunburn in the last summer (dichotomous variable), we constructed three generalized 121 linear models (GLM) of the Poisson family with a log link function and robust standard errors. We 122 decided to use the Poisson family instead of logistic regression to avoid overestimating the 123 calculated associations, especially because the prevalence of sunburns (outcome) was $>10 \%$ 
124 (27,28). Model 1 included sociodemographic characteristics (age, sex, marital status, and level of 125 education). Model 2 included Model $1+$ sun exposure habits and practices. Finally, model 3 126 included model $2+$ the skin phototype variable. We opted for this selection process in order to 127 achieve better control of confounding factors. In addition, we compared the final model with de 128 Model 2 using the log-likelihood ratio test. Since we obtained a $p<0.05$, we considered that the 129 block of variables included in Model 3 was relevant to explaining the outcome.

130

131 All regression models reported the adjusted prevalence ratio (aPR) with their respective 95\% CI 132 (95\% CI). The statistical analysis was carried out using the statistical package Stata v15.0 133 (StataCorp, TX, USA).

135 Ethics

136 The Institutional Review Board of the Hospital San Bartolomé (RCEI-40) in Lima, Peru, approved 137 the primary study. Participation in the survey was voluntary, and all the participants provided their 138 oral consent.

\section{RESULTS}

\section{Characteristics of the study population and history of sunburns}

142 We analyzed a total of 402 beachgoers of both sexes. A total of $232(57.7 \%)$ were female, 152 $143(37.8 \%)$ had no sunburn, $225(56.0 \%)$ had one to five sunburns and $25(6.2 \%)$ had six or more.

144 Table 1 shows the study population's characteristics according to the number of sunburns in the 145 last summer. 


\section{Factors associated with sunburns}

148 Table 2 shows the Poisson regression models' results for assessing the factors associated with 149 having had at least one sunburn in the last summer. In Model 1, no associated factors were 150 identified. In model 2, some associated factors were added, such as not avoiding sun exposure 151 during midday $(\mathrm{p}=0.019)$ and having sunbathed on the beach from one to 15 days $(\mathrm{p}=0.011)$ or 152 more than 15 days $(p=0.004)$ in the last two summers. Finally, Model 3 showed that the frequency 153 of having had at least one sunburn in the last summer was significantly higher among those with 154 a non-regular wearing of hat or cap $(\mathrm{p}=0.040)$, and those who spent one to 15 days $(\mathrm{p}=0.003)$ or 155 more than 15 days $(\mathrm{p}<0.001)$ sunbathing on the beach. On the other hand, having at least one 156 sunburn was less frequent with skin phototype III $(\mathrm{p}=0.038)$ or IV $(\mathrm{p}<0.001)$.

157

158

159

160

161

162 163 164 165 166 167 168 169

\section{DISCUSSION}

\section{Main results}

In our study sample, we found different factors associated with sunburns in people who went to a beach in northern Peru. Having skin phototype III or IV was associated with a lower frequency of sunburn. However, going to the beach for 1 to 15 days, more than 15 days, and not wearing a hat or cap regularly were associated with a higher frequency.

\section{Sunburns frequency}

More than a half $(62.2 \%)$ of the beachgoers reported having had at least one sunburn in the last two summers in our study sample. A previous study in beachgoers and skaters from Costa del Sol, Spain, found a lower sunburn frequency (46.9 and 56.8\%, respectively) $(15,23)$. However, another study conducted in a sample of beach handball players from Spain found a higher sunburn 
170 frequency ( $76.9 \%$ had at least one sunburn in the last year) (29). These sunburn events could be

171 related to prolonged sun exposure among the populations mentioned, in addition to insufficient

172 sun protection measures (30).

173

\section{Factors associated with sunburns}

175 Regarding the use of hats or caps, in our study, the non-regular use of these accessories was 176 associated with a higher prevalence of sunburn. This result is explained by a previous study by 177 Backes C et al (2018), in which the effectiveness of using hats for sun protection was assessed. 178 They found that not wearing this accessory and inadequate face protection in the midday hours of 179 summer were associated with receiving higher doses of solar ultraviolet radiation (UVR) (31).

Regarding the frequency of sunbathing on the beach in the last two summers, bathers who 182 sunbathed at least one day had a higher frequency of sunburns. This frequency was even higher among those who sunbathed for more than 15 days. These are expected results since one person is more vulnerable to sunburns if there are no adequate sun protection measures and more prolonged sun exposure $(18,24,32)$.

Beachgoers with a skin phototype type III-IV showed a lower frequency of sunburns in the last two summers. An explanation for this result is based on the Fitzpatrick's study which showed that the skin phototype IV rarely suffers sunburns and develops a tan more easily. In addition, although adults with skin phototype III may also have some risk of suffering from sunburns, its risk is lower than skin phototypes type I and II $(33,34)$. 
194 Like previous studies $(11,24,35)$, our analysis highlights the presence of several problems, such as 195 inadequate knowledge about sun protection, overexposure to the sun and a high prevalence of 196 sunburns. Health policies that encourage sunscreen use and public health campaigns aimed to 197 increase awareness about the health risks of UV exposure are urgently needed, emphasizing 198 populations at risk (36), such as beachgoers and tourists.

199

200 In Peru, every first Sunday of February, we celebrate "El día del lunar", a national awareness day 201 where medical campaigns are carried out along with informative talks. These activities' main 202 objective is to raise awareness about the health risks of prolonged sun exposure (35) and skin 203 cancer $(11,37)$.

204

205 Peru must adopt evidence-based strategies. For example, in Australia, some cross-sectional studies 206 assessed the impact of sun protection campaigns. These campaigns are delivered through the media 207 during the summer, with favorable results reported $(38,39)$. Likewise, these studies recognize that 208 awareness campaigns contribute to the short-term increase of some sun protection behaviors. Similarly, New Zealand has middle school programs that include teaching preventing practices to avoid overexposure to the sun and developing appropriate attitudes and habits at an early age (40).

211 In Latin America, there are incomplete and heterogeneous reports of the preventive measures 212 adopted by the countries (41). Therefore, it is necessary to carry out studies that prospectively 213 evaluate the impact of campaigns or other activities in reducing skin cancer incidence. 214

\section{LIMITATIONS}


216 The present study has some limitations. First, the possibility of social desirability bias. The

217 beachgoers could have responded according to the sun protection measures presented in the media

218 or their previous knowledge, reporting sun protection habits that they do not practice. Second, we

219 did not assess the effect of some variables that could potentially influence our study results, such

220 as current or past illnesses and a family history of skin cancer. Third, our study does not represent

221 the Pimentel district's demography because many beachgoers come to vacation from other cities,

222 regions, and countries during the summer. The study also does not necessarily represent the

223 expected frequencies to be found in subsequent studies since population and climatic conditions

224 may vary.

225

226 Despite these limitations, this study is one of the first in the local context to assess factors 227 associated with sunburns. There are previous studies that aimed to describe the knowledge, habits, 228 and attitudes about photoprotection. However, they were conducted in different populations, such 229 as outpatients, farmers, and company workers (42-44). Only two studies by Ramos W et al. 230 assessed the knowledge, attitudes, and practices of sun protection in a sample of beachgoers and 231 parents who went to beaches in Lima, Peru $(45,46)$. Additionally, although our study has an 232 exploratory approach, it allowed the construction of different models adjusting for blocks of 233 variables, which would increase the robustness of our findings.

234

235 CONCLUSION

236 Three out of five beachgoers had experience one or more sunburns in the last summer. The factors 237 associated with a higher frequency were the time of sun exposure and the non-regular use of a hat 238 or cap at the beach. Skin phototypes III-IV were associated with a lower frequency of sunburn. 


\section{ACKNOWLEDGEMENT}

240 To Sara Burgos, Luz Vargas, Jhosuny Perez, Otto Vargas and Ruth Burgos, who participated in 241 the primary study's data collection.

243 FUNDING

244 This study was partially funded by the Universidad Santo Toribio de Mogrovejo, Chiclayo, Peru. 245

246

COMPETING INTERESTS

247 The authors declare that there are no competing interests.

248

249 AUTHOR CONTRIBUTIONS

250 CJTH conceived the idea and design of the study. All authors participated in the analysis and 251 interpretation of the data, drafting of the final manuscript and its approval for publication.

252

\section{REFERENCES}

254 1. Apalla Z, Lallas A, Sotiriou E, Lazaridou E, Ioannides D. Epidemiological trends in skin 255 cancer. Dermatol Pract Concept. 2017;7(2):1-6.

256 2. Bray F, Ferlay J, Soerjomataram I, Siegel RL, Torre LA, Jemal A. Global cancer statistics 257 2018: GLOBOCAN estimates of incidence and mortality worldwide for 36 cancers in 185 countries. CA Cancer J Clin. 2018;68(6):394-424.

259

3. World Health Organization. Radiation: Ultraviolet (UV) radiation and skin cancer [Internet]. Switzerland: WHO; 2017. Available from: https://www.who.int/news-room/q-adetail/ultraviolet-(uv)-radiation-and-skin-cancer 
262 4. Guy GP, Machlin SR, Ekwueme DU, Yabroff KR. Prevalence and costs of skin cancer 263 treatment in the U.S., 2002-2006 and 2007-2011. Am J Prev Med. 2015;48(2):183-7.

264 5. Gordon LG, Elliott TM, Wright CY, Deghaye N, Visser W. Modelling the healthcare costs 265 of skin cancer in South Africa. BMC Health Serv Res. 2016;16:113.

266 6. Doran CM, Ling R, Byrnes J, Crane M, Searles A, Perez D, et al. Estimating the economic 267 costs of skin cancer in New South Wales, Australia. BMC Public Health. 2015;15:952.

268 7. Liley JB, McKenzie RL. Where on Earth has the highest UV. In: National Institute of Water 269 \& Atmospheric Research, UV Radiation and its Effects: An Update (2006). Workshop $270 \quad$ Proceedings. 2006;26-37.

271 8. Servicio Nacional de Meteorología e Hidrología. Perú: SENAMHI; 2017. Available from: 272 https://www.senamhi.gob.pe/

273 9. Ministerio de Salud, Dirección General de Epideimología. Boletín Epidemiológico (Lima), 274 Volumen 22 - Semana Epidemiológica No 11. Perú: DGE; 2013. Available from: 275 www.dge.gob.pe/portal/docs/vigilancia/boletines/2013/11.pdf.

276 10. Ministerio de Salud, Centro Nacional de Epidemiología, Prevención y Control de 277 Enfermedades. Boletión Epidemiológico del Perú, Volumen 27 - SE 31. Perú: CDC; 2018. 278 Available from: https://www.dge.gob.pe/portal/docs/vigilancia/boletines/2018/31.pdf.

279 11. Holman DM, Ding H, Guy GP, Watson M, Hartman AM, Perna FM. Prevalence of sun 280 protection use and sunburn and association of demographic and behaviorial characteristics with sunburn among US adults. JAMA Dermatology. 2018;154(5):561-8.

282 12. Bruce AF, Theeke L, Mallow J. A state of the science on influential factors related to sun protective behaviors to prevent skin cancer in adults. Int J Nurs Sci. 2017;4(3):225-35.

284 13. O'Riordan DL, Steffen AD, Lunde KB, Gies P. A day at the beach while on tropical 
vacation: Sun protection practices in a high-risk setting for UV radiation exposure. Arch Dermatol. 2008;144(11):1449-55.

287 14. Heerfordt IM, Philipsen PA, Larsen B, Wulf HC. Long-term trend in sunscreen use among beachgoers in Denmark. Acta Derm Venereol. 2017;97(10):1202-5.

15. de Troya-Martín M, Delgado-Sánchez N, Blázquez-Sánchez N, Ortega-Tudela G, ToribioMontero JC, Jabalera-Mesa ML, Ríos-Almellones I, Rivas-Ruiz F. Skin cancer prevention campaign aimed at beachgoers on the costa del Sol (southern Spain). Int J Dermatol. 2014;53(11):e526-30.

293

294

295

296

297

298

299

300

301

302

303

304

305

306

16. Cercato MC, Ramazzotti V, Sperduti I, Asensio-Pascual A, Ribes I, Guillén C, et al. Sun Protection Among Spanish Beachgoers: Knowledge, Attitude and Behaviour. J Cancer Educ. 2015;30(1):4-11.

17. Robinson NG, White KM, Hamilton K, Starfelt LC. Predicting the sun-protective decisions of young female Australian beachgoers. J Health Psychol. 2016;21(8):1718-27.

18. Marion JW, Lee J, Rosenblum JS, Buckley TJ. Assessment of temperature and ultraviolet radiation effects on sunburn incidence at an inland U.S. Beach: A cohort study. Environ Res. 2018;161:479-84.

19. Diffey B. Sunburn and ambient temperature. Br J Dermatol. 2018;178(2):e124..

20. Holman DM, Ding H, Berkowitz Z, Hartman AM, Perna FM. Sunburn prevalence among US adults, National Health Interview Survey 2005, 2010, and 2015. J Am Acad Dermatol. 2019;80(3):817-20.

21. Arutyunyan S, Alfonso S V., Hernandez N, Favreau T, Isabel Fernández M. Predictors of sunburn risk among Florida residents. J Am Osteopath Assoc. 2017 1;117(3):150-7.

22. Pinault L, Fioletov V. Sun exposure, sun protection and sunburn among Canadian adults. 
$308 \quad$ Health Rep. 2017;28(5):12-9.

309 23. Toro-Huamanchumo CJ, Burgos-Muñoz SJ, Vargas-Tineo LM, Perez-Fernandez J, Vargas310 Tineo OW, Burgos-Muñoz RM, Zentner-Guevara JA, Bada C. Awareness, behavior and 311 attitudes concerning sun exposure among beachgoers in the northern coast of Peru. PeerJ. $312 \quad 2019 ; 2019(1):$ e6189.

313 24. de Troya-Martín M, de Gálvez-Aranda MV, Rivas-Ruiz F, Blázquez-Sánchez N, 314 Fernández-Morano MT, Padilla-España L, Herrera-Ceballos E. Prevalence and predictors 315 of sunburn among beachgoers. Photodermatol Photoimmunol Photomed. 2018;34(2):1223169.

317 25. Instituto Nacional de Defensa Civil. Pimentel. Mapa de Peligros de Pimentel. Perú: $318 \quad$ INDECI; 2003.

319 26. Sánchez G, Nova J. Confiabilidad y reproducibilidad de la escala de fototipos de Fitzpatrick 320 antes y después de un ejercicio de estandarización clínica. Biomedica. 2008;28(4):544-50.

321 27. Barros AJD, Hirakata VN. Alternatives for logistic regression in cross-sectional studies: An 322 empirical comparison of models that directly estimate the prevalence ratio. BMC Med Res Methodol. 2003 20;3:1-13.

324

28. Tamhane AR, Westfall AO, Burkholder GA, Cutter GR. Prevalence odds ratio versus 325 prevalence ratio: choice comes with consequences. Stat Med. 2016 30;35(30):5730-5.

29. De Castro-Maqueda G, Gutierrez-Manzanedo JV, Lagares-Franco C, Linares-Barrios M, 327 328 De Troya-Martin M. Photoprotection practices, knowledge and sun-related skin damage in Spanish beach handball players. PeerJ. 2019;2019(6):e7030.

30. DeFlorio-Barker S, Holman D, Landolfi R, Arnold BF, Colford JM, Weisberg SB, Schiff 330 KC, Sams EA, Wade TJ. Incidence and public health burden of sunburn among beachgoers 
in the United States. Prev Med (Baltim). 2020;134:106047.

332 31. Backes C, Religi A, Moccozet L, Vuilleumier L, Vernez D, Bulliard JL. Facial exposure to 333 ultraviolet radiation: Predicted sun protection effectiveness of various hat styles. 334 Photodermatol Photoimmunol Photomed. 2018;34(5):330-337.

335 32. Makin JK, Warne CD, Dobbinson SJ, Wakefield MA, Hill DJ. Population and age-group trends in weekend sun protection and sunburn over two decades of the SunSmart programme in Melbourne, Australia. Br J Dermatol. 2013 Jan;168(1):154-61.

33. Coelho SG, Choi W, Brenner M, Miyamura Y, Yamaguchi Y, Wolber R, Smuda C, Batzer J, Kolbe L, Ito S, Wakamatsu K, Zmudzka BZ, Beer JZ, Miller SA, Hearing VJ. Short- and long-term effects of UV radiation on the pigmentation of human skin. J Investig Dermatol Symp Proc. 2009;14(1):32-5.

342 34. Castanedo-Cazares JP, Hernández-Blanco D, García-Cortés JD, Medina-Aguilar L, TorresÁlvarez B. Análisis de la pigmentación cutánea en una muestra. Gac Med Mex. 2018;154(1):68-73.

35. Sordo C, Gutiérrez C. Cáncer de piel y radiación solar: experiencia peruana en la prevención y detección temprana del cáncer de piel y melanoma. Rev Peru Med Exp Salud Publica. 2013;30(1):113-7.

36. Strickland M, Fritschi L. Communicating the epidemiology of skin cancer - is anybody listening? Australas Epidemiol. 2014;21(1):35.

37. Erdmann F, Lortet-Tieulent J, Schüz J, Zeeb H, Greinert R, Breitbart EW, et al. International trends in the incidence of malignant melanoma 1953-2008-are recent generations at higher or lower risk? Int J Cancer. 2013;132(2):385-400.

353 38. Smith BJ, Ferguson C, McKenzie J, Bauman A, Vita P. Impacts from repeated mass media 
campaigns to promote sun protection in Australia. Health Promot Int. 2002;17(1):51-60.

355

356

357

358

359

360

361

362

363

364

365

366

367

368

369

370

371

372

373

374

375

376

39. Koch S, Pettigrew S, Strickland M, Slevin T, Minto C. Sunscreen Increasingly Overshadows Alternative Sun-Protection Strategies. J Cancer Educ. 2017;32(3):528-31.

40. McNoe BM, Reeder AI. Sun protection policies and practices in New Zealand primary schools. N Z Med J. 2019;132(1497):46-54.

41. de Vries E, Sierra M, Piñeros M, Loria D, Forman D. The burden of cutaneous melanoma and status of preventive measures in Central and South America. Cancer Epidemiol. 2016 Sep 1;44:S100-9.

42. Thomas-Gavelan E, Sáenz-Anduaga E, Ramos W, Sánchez-Saldaña L, del Carmen Sialer M. Knowledge, attitudes and practices about sun exposure and photoprotection in outpatients attending dermatology clinics at four hospitals in Lima, Peru. An Bras Dermatol. $2011 ; 86(6): 1122-8$.

43. Cueva-Puelles L, Urdanivia-Cotrina M, Valle-Bedregal A, Aponte-Villacorta JE, DávilaRequelme L, Morales-Olivera S, Arrascue-Sánchez G, Ñique-Carbajal CA, MonsalveMera A. Conocimientos y hábitos sobre protección solar en agricultores del caserío de Macuaco, Chiclayo, Perú, 2019. Rev Exp Med. 2020;5(4):173-8.

44. Mejía CR, Chacón JI, Hernández-Calderón N, Talledo-Ulfe L-C, Vega-Melgar VI, RazaVásquez LE, Astocondor-Altamirano J, Cardenas MM. Protección contra la radiación solar en trabajadores de empresas peruanas: prácticas y cuidado personal, 2016. Dermatol Rev Mex. 2018;62(2):101-10.

45. Ramos W, Sánchez-Saldaña L, Canales L, Ponce-Rodríguez M, Moisés C, Espinoza H, Fuertes-Anaya MC. Conocimientos, actitudes, prácticas de fotoprotección de bañistas que acuden a playas de Lima. Dermatol Peru. 2013;22(4):140-54. 
377 46. Ramos W, Sánchez-Saldaña L, Casanova E, Fuertes-Anaya MC, Guerrero N, Chalco M, 378 Silloca-Cabana E. Conocimientos, actitudes y prácticas de fotoprotección infantil de padres 379 de familia que acuden a dos playas de Lima. Febrero 2013. Dermatol Peru. 2017;27(3):144380 9

381 


\section{Table $\mathbf{1}$ (on next page)}

Sociodemographic characteristics, skin phototype, habits, and sun protection practices, according to sunburn history $(n=402)$

SPF: Sun protection factor *Median [IQR] ${ }^{* *}$ Chi2 test $\uparrow$ Fisher exact test $\ddagger$ Kruskal Wallis test 
1 Table 1. Sociodemographic characteristics, skin phototype, habits, and sun protection practices, 2 according to sunburn history $(n=402)$

\begin{tabular}{|c|c|c|c|c|}
\hline \multirow[b]{2}{*}{ Variables } & \multicolumn{2}{|c|}{ Sunburn history } & \multirow[b]{2}{*}{ 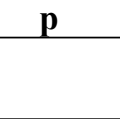 } & \multirow{2}{*}{$\begin{array}{l}\text { SPF: Sun } \\
\text { protection } \\
\text { factor } \\
{ }^{* *} \text { Chi2 test }\end{array}$} \\
\hline & $\begin{array}{c}\text { None } \\
(\mathrm{n}=152)\end{array}$ & $\begin{array}{c}\geq 1 \\
(\mathrm{n}=\mathbf{2 5 0})\end{array}$ & & \\
\hline Age & & & $0.543^{* *}$ & $\dagger$ Fisher \\
\hline Young adult & $81(36.5)$ & $141(63.5)$ & & exact test \\
\hline Adult & $71(39.4)$ & $109(60.6)$ & & \\
\hline Sex & & & $0.528^{* *}$ & \\
\hline Male & $62(36.1)$ & $110(63.9)$ & & \\
\hline Female & $90(39.1)$ & $140(60.9)$ & & \\
\hline Marital status & & & $0.635^{* *}$ & \\
\hline Single/ Widowed/ Divorced/ separated & $90(38.8)$ & $142(61.2)$ & & \\
\hline Married or cohabiting & $62(36.5)$ & $108(63.5)$ & & \\
\hline Nationality & & & $0.403^{\dagger}$ & \\
\hline Peru & $148(37.6)$ & $246(62.4)$ & & \\
\hline Argentina & $2(100.0)$ & $0(0.0)$ & & \\
\hline Colombia & $1(33.3)$ & $2(66.7)$ & & \\
\hline Ecuador & $1(50.0)$ & $1(50.0)$ & & \\
\hline Mexico & $0(0.0)$ & $1(100.0)$ & & \\
\hline Level of education & & & $0.606^{* *}$ & \\
\hline None or school & $58(39.5)$ & $89(60.5)$ & & \\
\hline Higher education & $94(36.9)$ & $161(63.1)$ & & \\
\hline Skin phototype & & & $0.001^{* *}$ & \\
\hline I & $11(18.3)$ & $49(81.7)$ & & \\
\hline II & $22(27.8)$ & $57(72.2)$ & & \\
\hline III & $47(28.8)$ & $116(71.2)$ & & \\
\hline IV & $72(72.0)$ & $28(28.0)$ & & \\
\hline Sun exposure habits in the last two summers: & & & & \\
\hline Days spent sunbathing on the beach & & & $0.001^{* *}$ & \\
\hline None & $32(59.3)$ & $22(40.7)$ & & \\
\hline $1-15$ days & $101(35.8)$ & $181(64.2)$ & & \\
\hline More than 15 days & $19(28.8)$ & $47(71.2)$ & & \\
\hline Hours per day exposed to the sun on the beach & & & $0.025^{* *}$ & \\
\hline Less than 30 minutes & $35(52.2)$ & $32(47.8)$ & & \\
\hline 30 minutes to one hour & $35(37.2)$ & $59(62.8)$ & & \\
\hline More than one hour & $82(34.0)$ & $159(66.0)$ & & \\
\hline Sun protection practice in the beach: & & & & \\
\hline Non-regular using of a beach umbrella & $88(39.1)$ & $137(60.9)$ & $0.544^{* *}$ & \\
\hline Non-regular wearing of a hat or cap & $76(35.7)$ & $137(64.3)$ & $0.350^{* *}$ & \\
\hline Non-regular wearing long-sleeved clothing & $120(37.0)$ & $204(63.0)$ & $0.514^{* *}$ & \\
\hline $\begin{array}{l}\text { Non-regular avoiding of sun exposure during the } \\
\text { midday }\end{array}$ & $75(32.1)$ & $159(68.0)$ & $0.005^{* *}$ & \\
\hline Non-regular using of sunscreen with a SPF $\geq 15$ & $50(34.2)$ & $96(65.8)$ & $0.266^{* *}$ & \\
\hline
\end{tabular}




\section{Table 2 (on next page)}

Factors associated with sunburns $(n=402)$

aPR: Adjusted prevalence ratio SPF: Sun protection factor 95\% Cl: $95 \%$ confidence intervals 


\section{Table 2. Factors associated with sunburns $(n=402)$}

\begin{tabular}{|c|c|c|c|c|c|c|c|c|c|}
\hline \multirow{2}{*}{ Variables } & \multicolumn{3}{|c|}{ Model 1} & \multicolumn{3}{|c|}{ Model 2} & \multicolumn{3}{|c|}{ Model 3} \\
\hline & aPR & $95 \%$ CI & $\mathbf{p}$ & aPR & $95 \% \mathrm{CI}$ & $\mathbf{p}$ & aPR & $95 \% \mathrm{CI}$ & p \\
\hline Age (adults) & 0.96 & $(0.90-1.03)$ & 0.300 & 0.98 & $(0.91-1.05)$ & 0.493 & 0.98 & $(0.93-1.05)$ & 0.614 \\
\hline Sex (females) & 0.98 & $(0.93-1.04)$ & 0.527 & 1.01 & $(0.95-1.07)$ & 0.895 & 0.99 & $(0.94-1.05)$ & 0.786 \\
\hline \multicolumn{10}{|l|}{ Marital status } \\
\hline Single & Ref. & & & Ref. & & & Ref. & & \\
\hline Married or cohabiting & 1.03 & $(0.97-1.11)$ & 0.291 & 1.03 & $(0.96-1.10)$ & 0.380 & 0.99 & $(0.93-1.05)$ & 0.662 \\
\hline \multicolumn{10}{|l|}{ Leve of education } \\
\hline None or school & Ref. & & & Ref. & & & Ref. & & \\
\hline Higher education & 1.01 & $(0.95-1.08)$ & 0.705 & 1.03 & $(0.97-1.09)$ & 0.403 & 0.99 & $(0.93-1.04)$ & 0.643 \\
\hline \multicolumn{10}{|l|}{$\begin{array}{l}\text { Days spent sunbathing on the beach in the last } \\
\text { two summers }\end{array}$} \\
\hline None & & & & Ref. & & & Ref. & & \\
\hline $1-15$ days & & & & 1.14 & $(1.03-1.26)$ & 0.011 & 1.16 & $(1.05-1.27)$ & 0.003 \\
\hline More than 15 days & & & & 1.19 & $(1.06-1.35)$ & 0.004 & 1.22 & $(1.09-1.36)$ & $<0.001$ \\
\hline \multicolumn{10}{|l|}{$\begin{array}{l}\text { Hours spent sunbathing on the beach in the last } \\
\text { two summers }\end{array}$} \\
\hline Less than 30 minutes & & & & Ref. & & & Ref. & & \\
\hline 30 minutes to one hour & & & & 1.06 & $(0.96-1.17)$ & 0.245 & 1.08 & $(0.98-1.19)$ & 0.122 \\
\hline More than one hour & & & & 1.05 & $(0.96-1.15)$ & 0.313 & 1.06 & $(0.97-1.16)$ & 0.200 \\
\hline Non-regular using of a beach umbrella & & & & 0.98 & $(0.92-1.04)$ & 0.411 & 0.98 & $(0.93-1.04)$ & 0.509 \\
\hline Non-regular wearing of a hat or cap & & & & 1.02 & $(0.96-1.08)$ & 0.551 & 1.06 & $(1.01-1.12)$ & 0.040 \\
\hline Non-regular wearing long-sleeved clothing & & & & 1.01 & $(0.93-1.09)$ & 0.856 & 1.02 & $(0.95-1.10)$ & 0.609 \\
\hline $\begin{array}{l}\text { Non-regular avoiding of sun exposure during } \\
\text { midday }\end{array}$ & & & & 1.07 & $(1.01-1.14)$ & 0.019 & 1.04 & $(0.99-1.10)$ & 0.146 \\
\hline Non-regular using of sunscreen with a SPF $\geq 15$ & & & & 1.04 & $(0.98-1.11)$ & 0.203 & 1.05 & $(1.00-1.11)$ & 0.072 \\
\hline \multicolumn{10}{|l|}{ Skin phototype } \\
\hline I & & & & & & & Ref. & & \\
\hline II & & & & & & & 0.95 & $(0.89-1.02)$ & 0.175 \\
\hline III & & & & & & & 0.94 & $(0.88-0.99)$ & $\mathbf{0 . 0 3 8}$ \\
\hline IV & & & & & & & 0.69 & $(0.63-0.75)$ & $<0.001$ \\
\hline
\end{tabular}

aPR: Adjusted prevalence ratio

SPF: Sun protection factor

95\% CI: 95\% confidence intervals

3

4 